IRA-International Journal of Applied Sciences ISSN 2455-4499; Vol.06, Issue 01 (2017)

Institute of Research Advances

Pg. no. 9-14

http://research-advances.org/index.php/IRAJAS

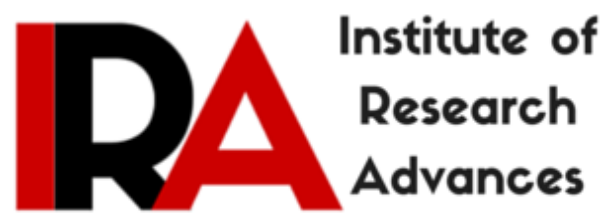

\title{
Epidemiological Analysis of Burns Patients with Pregnancy in a Tertiary Care Centre
}

\author{
Dr B. Shankari M.Ch ${ }^{1}$ \\ Dr B. Rajeswari M. $\mathrm{Ch}^{2}$ \\ Prof. Angeline Selvaraj M.Ch ${ }^{3}$ \\ ${ }^{1,2,3}$ Kilpauk Medical College Hospital, Chennai, India.
}

Type of Review: Peer Reviewed.

DOI: $\underline{\text { http://dx.doi.org/10.21013/jas.v6.n1.p2 }}$

\section{How to cite this paper:}

Shankari, B., Rajeswari, B., \& Selvaraj, A. (2017). Epidemiological Analysis of Burns Patients with Pregnancy in a Tertiary Care Centre. IRA-International Journal of Applied Sciences (ISSN 2455-4499), 6(1), 9-14. doi:http://dx.doi.org/10.21013/jas.v6.n1.p2

(C) Institute of Research Advances

\section{(cc) EY-NC}

This work is licensed under a Creative Commons Attribution-Non Commercial 4.0 International License subject to proper citation to the publication source of the work.

Disclaimer: The scholarly papers as reviewed and published by the Institute of Research Advances (IRA) are the views and opinions of their respective authors and are not the views or opinions of the IRA. The IRA disclaims of any harm or loss caused due to the published content to any party. 


\begin{tabular}{|c|} 
ABSTRACT \\
Burns during pregnancy is a serious threat to the life of the mother as well as the baby. \\
Burns suffered during pregnancy is rare and can be a devastating injury. Burns during pregnancy can \\
influence maternal as well as foetal outcome. It is also associated with various social and economic \\
problems which complicate the rehabilitation. Keeping this in view, a comprehensive task was \\
undertaken to assess the maternal and foetal outcome in relation to burns extent and gestation.
\end{tabular}

\section{Introduction}

Every year, in our Centre at Government Kilpauk Medical College Hospital, more than 1,500 people with severe burns require medical intervention. According, to the International society for injuries caused by burn, burn is a damage to the skin or other organs which is caused by thermal source. Burns occurs when a part of all of the cells of the skin or body tissues are destroyed by hot liquids, hot objects or flame. Burns are always considered as one of the most devastating injury leading to death or disability. It also has major economic consequences and severe long-term mental and physical complications.

In developing countries like India, burns in women of reproductive age occur more frequently when compared to those in developed countries. Thermal injuries sustained during pregnancy presents special problem for the gravid woman and her foetus. This study was carried out to determine the maternal and foetal outcome in relation to burn extent and gestational age of foetus.

Epidemiological studies of burns in different parts of country show that young people, women and those with low educational level are more common victims of burns. Reproductive age is the most important stage of life.

The most positive health characteristics are observed in this age group. Few studies are done on mortality caused by burns in this age group, especially during pregnancy.

Physiological changes during pregnancy affect the patient with burns during this period. Thermal burns during pregnancy have many side effects and are associated with a high incidence of complications such as intrauterine foetal death, miscarriage and preterm birth.

The factors that play a role in the survival of the mother and foetus are as follows:

1. Body Surface burn percentage.

2. Gestational age.

3. Depth of the wound.

4. Burn complications.

5. Accompanied of Medical illness and other injuries.

Management of burns during pregnancy needs a Team approach with close monitoring of the mother and the foetus. In most cases, Foetal health directly depends on mother's health. This study was conducted for a 1-year period to determine the Epidemiological factors and burn outcomes in pregnant women admitted to Kilpauk Medical College Hospital in Chennai.

\section{Materials_and_methods}

This retrospective study was carried out for a period of 1 year from January 2015 to December 2015.

A total of thirty pregnant burns women in the age group 15- 40 years admitted to our burns unit were analysed. The medical records and documents of all the pregnant women with burns who were admitted to our hospital were examined.

The required data including age, burn percentage, cause of burns, extent and severity of burns, gestational age and foetal and maternal outcomes were collected. The extent of burns is estimated on the basis of the burn percentage of total body surface area (TSBA) using the Lund and Browder Chart. In order to clinically assess the severity of burns, a four-grade classification was used. 
The maternal and the foetal outcomes were also analysed. The data collected was entered into a standard proforma prepared for this study and were analysed. On the basis of the analysis and observations, results were drawn and discussed with the other relevant literatures.

\section{Results}

In this study, 30 cases of pregnant burn victims in the age group of 15-35 years were assessed. The gestational age of these patients varied from eight weeks to 34 weeks with 11 cases in first trimester, 13 in second trimester and 6 in the third trimester.

The mean burn percentage of body surface area was from $10 \%$ to 95\% TSBA. The patients were categorized based on their trimester and their burn extent.

In burns, up to $25 \%$ TSBA, there were no deaths in the $1^{\text {st }}$ and $2^{\text {nd }}$ trimester. One out of the two cases in the third trimester died due to septicaemia. There was no other foetal death or obstetric complications in any of these patients.

Burns of 26\%-50\% TSBA led to maternal death in all cases in the first trimester. Out of the 6 cases in $2^{\text {nd }}$ trimester two patients survived in which one had spontaneous expulsion of dead foetus. The other continued her pregnancy. On the $3^{\text {rd }}$ trimester out of the 3 cases only one patient died. The other two were discharged with healthy foetus. with foetal death.

In Burns of 51\%- $75 \%$ and $76 \%-100 \%$ TSBA, there was mortality of all the patients along Maternal and foetal outcome in relation to TBSA are shown in the following tables.

\section{Total no of cases in each trimester.}

\begin{tabular}{|l|l|}
\hline $1^{\text {ST }}$ Trimester & $11(36 \%)$ \\
\hline $2^{\text {nd }}$ Trimester & $13(43 \%)$ \\
\hline $3^{\text {rd }}$ Trimester & $6(21 \%)$ \\
& \\
\hline
\end{tabular}

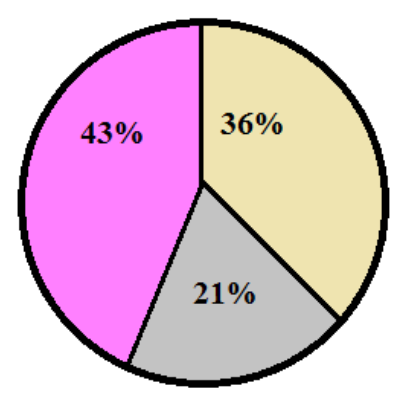

1st Trimester

2nd Trimester

3rd Trimester

Total no of cases in each \% of TSBA

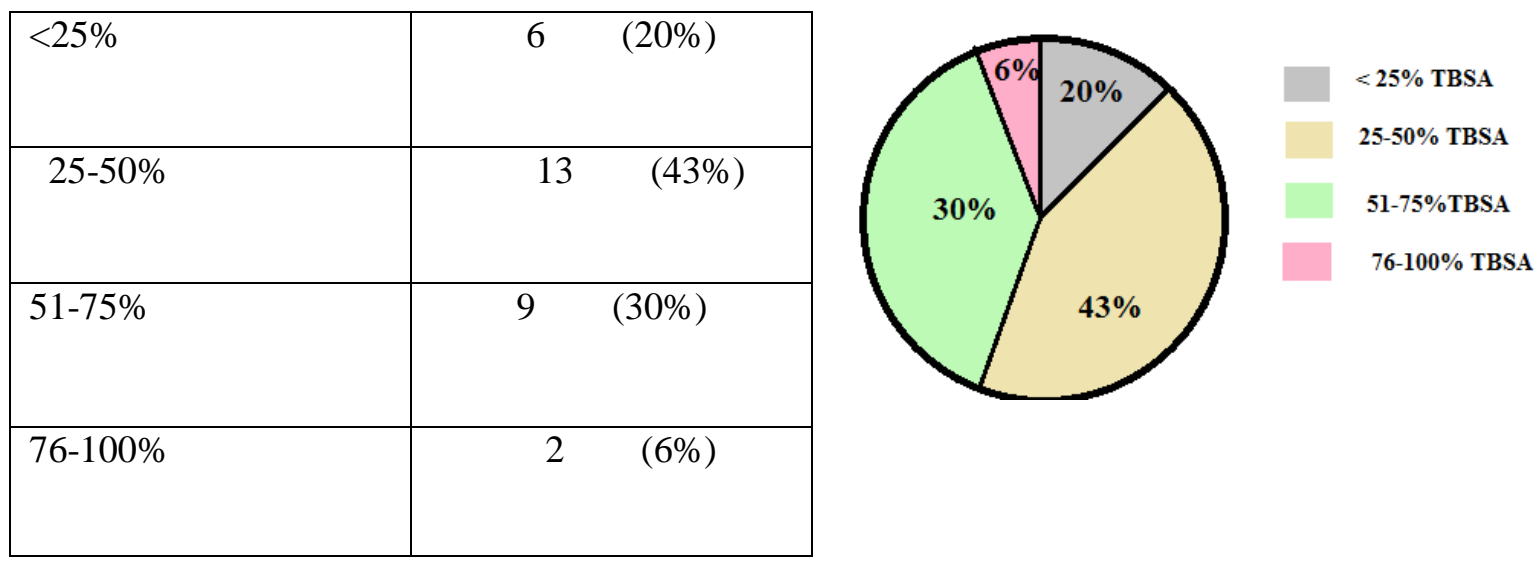


Distribution of burns extent in $1^{\text {st }}$ trimester

\begin{tabular}{|c|c|cc|cc|}
\hline & NO. OF CASES & \multicolumn{2}{|c|}{$\begin{array}{c}\text { NO. OF MATERNAL } \\
\text { DEATH }\end{array}$} & \multicolumn{2}{|c|}{$\begin{array}{c}\text { NO. OF CASES } \\
\text { ABORTED }\end{array}$} \\
\hline$<25 \%$ & 2 & 0 & $(0 \%)$ & 0 & $(0 \%)$ \\
\hline $25-50 \%$ & 4 & 4 & $(100 \%)$ & 4 & $(100 \%)$ \\
\hline $51-75 \%$ & 4 & 4 & $(100 \%)$ & 4 & $(100 \%)$ \\
\hline $76-100 \%$ & 1 & 1 & $(100 \%)$ & 1 & $(100 \%)$ \\
\hline
\end{tabular}

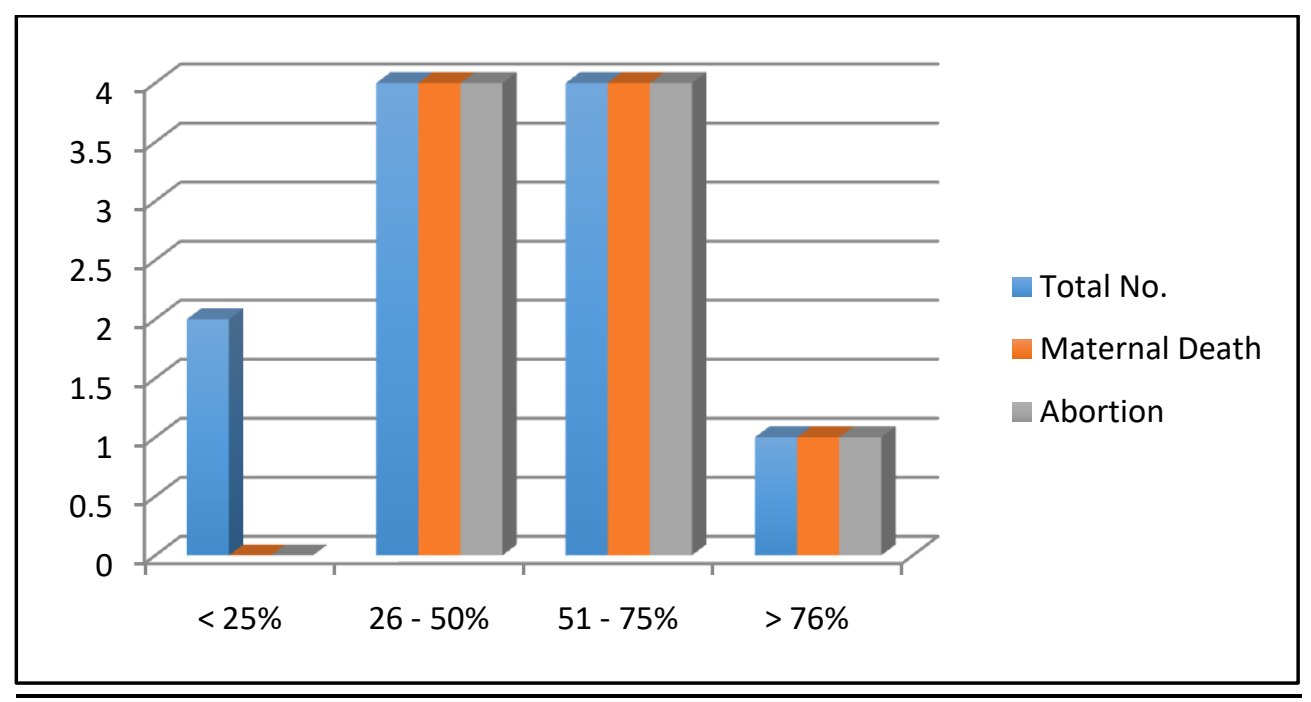

Distribution of burns extent in 2nd trimester

\begin{tabular}{|c|c|c|c|}
\hline & NO. OF CASES & $\begin{array}{l}\text { NO. OF MATERNAL } \\
\text { DEATH }\end{array}$ & $\begin{array}{lc}\text { NO. OF } & \text { CASES } \\
\text { ABORTED } & \end{array}$ \\
\hline$<25 \%$ & 2 & $\begin{array}{lll}0 & (0 \%) \\
\end{array}$ & $\begin{array}{ll}0 & (0 \%)\end{array}$ \\
\hline $25-50 \%$ & 6 & $4 \quad(65 \%)$ & $(16 \%)$ \\
\hline $51-75 \%$ & 4 & $4 \quad(100 \%)$ & $\begin{array}{ll}4 & (100 \%)\end{array}$ \\
\hline $76-100 \%$ & 1 & $1 \quad(100 \%)$ & $(100 \%)$ \\
\hline
\end{tabular}

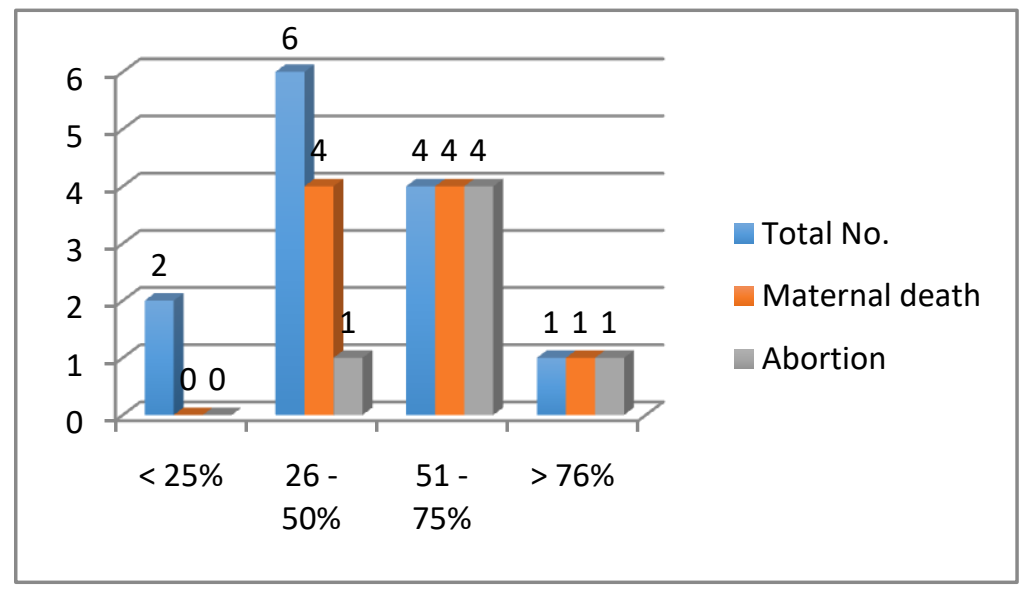


Distribution of burns extent in 3rd trimester

\begin{tabular}{|c|c|cc|cc|}
\hline & NO. OF CASES & \multicolumn{2}{|c|}{$\begin{array}{c}\text { NO. OF MATERNAL } \\
\text { DEATH }\end{array}$} & \multicolumn{2}{c|}{$\begin{array}{c}\text { NO. OF CASES } \\
\text { ABORTED }\end{array}$} \\
\hline$<25 \%$ & 2 & 1 & $(50 \%)$ & 1 & $(50 \%)$ \\
\hline $25-50 \%$ & 3 & 1 & $(33 \%)$ & 1 & $(33 \%)$ \\
\hline $51-75 \%$ & 1 & 1 & $(100 \%)$ & 1 & $(100 \%)$ \\
\hline $76-100 \%$ & - & - & $-(0 \%)$ & $-(0 \%)$ \\
\hline
\end{tabular}

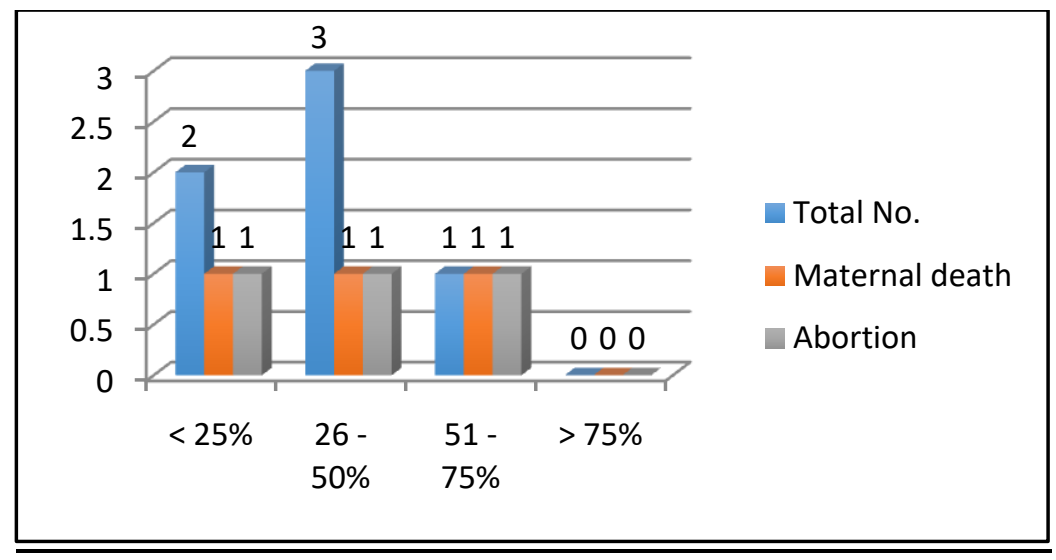

\section{Discussion}

Burns during pregnancy is not a common phenomenon but can have many side effects on maternal and foetal outcomes. Foetal outcomes heavily depends on maternal outcomes.

Hence, in order to minimise the maternal and foetal mortality rates, care should be given to pregnant women considering the foetal status. Treatment for pregnant women with burn requires a close co-operation between the Gynaecologists and the Burn Trauma Surgeon. Burns injury during pregnancy is a major problem in developing countries. This high prevalence is peculiar in our community probably because of illiteracy, unsafe cooking habits and our social custom of dowry.

In this study, it showed that abortions during the first trimester was $74 \%$, in the $2^{\text {nd }}$ trimester $54 \%$ and in the $3^{\text {rd }}$ trimester $61 \%$. This is in accordance with the finding of V. Mayo et al [6].This highlights that as far as pregnancy is concerned, burns has a deleterious effect on the foetus and proceed to abortion. It precipitates to abortions and premature labour on a very significant scale.

This study showed that maternal mortality increased with burns of $>25 \%$ with maximum in burn patients with more than 50\% TSBA. This is in accordance with the study of Rayburn et al [9].There is a positive relationship between the percentage of burns and the risk of maternal and foetal death.

In this study, most of the burns occurred in the age of 15-40 years of age. This is probably because of increasing familiar stress like cooking with unguarded fire, rearing of smaller children, overburdened household activities like living in an overcrowded space with minimal amenities leading to frequent accidents. Also in developing country like India, females are married at an early age and are more exposed to social and family stress

\section{Conclusion}

Burns suffered during pregnancy is rare and can be a devastating injury. From the relevant literature, it appears that the incidence of burns is not low especially in developing countries like India. The result of this study showed high maternal and foetal mortality rates in pregnant women with burns and these are significantly affected by the percentage of TSBA burned. 
It is reasonable to consider the possible integration of a focused injury prevention and also mental health promotion into the current prenatal care delivered to pregnant women.

Social, cultural and economic aspects may contribute to the incidence and their needs to be addressed through educational support. Hence, conducting educational programs and taking preventive measures play a major role in decreasing maternal and foetal morbidity rates caused by burns among the pregnant women. Also, we must emphasize the importance of planning and implementing standard supportive and therapeutic protocols for maintaining health of mother and foetus immediately after patient hospitalisation.

\section{References}

1. Shah NA, Patel VJ, Patel CV, et al. Epidemiological study of burns patient with pregnancy. Indian Journal of Burns 2006; 14: 44-6.

2. Guo SS. Greenspoon JS Khan A M. Management of burns injuries during pregnancy. Burns 2001; 27: 394-7.

3. Prasanna M, Singh K. Early burn wound excision in major burns with pregnancy. A preliminary report. Burns 22; 234-7 1996.

4. Taylor J, Plunkett G, MC Manus W et al. Thermal injuries during pregnancy. Obstetric Gynaecologists 1975; 47: 434-8.

5. Mathew RN. Obstetric Implications of burns in pregnancy. But J Obsetet Gynaecol 1982; 89:603.

6. Mago.V, Ahmed I, Kochar N; Barian LM Burnt pregnant wives: A social stigma. Burns 2005; 31: 175-7.

7. Yiagbei Z, Yingjie, Xuewi. W. Burns injury during pregnancy :An analysis of 24 cases ; Burns 1981; 8: 286-9.

8. MC Cauley RL, Stenberg BA, Phillips L.G, Blackwell SJ, Robson MC. Long Term assessment of the effects of circumferential truncal burns.

9. Rayburn W, Smith B, Feller I, Varner M; Guikshank D major burns during pregnancy. Effect on foetal well being.

10. Cheah SH, Sivanesaratnam V; Burns in pregnancy- maternal and foetal prognosis. Aust N.Z.J Obset Gynaecol 1989: 29:143-5.

11. Akhter MA, Mulawkar PM, Kulkarni HR. Burns in pregnancy effect on maternal and foetal outcomes. Burns 1999; 20:351-5.

12. Ambade V.N, Godhole H V, Study of burn deaths in Nagpur; Central India, Burns 2006; 32: 902-8. 